\title{
Pengaruh Inovasi Kuliner Pada Jajanan Cacalan Terhadap Keputusan Pembelian di Kecamatan Sidemen
}

\section{A.A Ketut Alit Pujawan*}

Program Studi Manajeen Tata Boga, Sekolah Tinggi Pariwisata Nusa Dua Bali

\section{A R T I C L E I N F O}

Article history:

Received 19 February 2018

Received in revised form 10 March 2018

Accepted 12 April 2018 Available online 25 May 2018

\section{Kata Kunci:}

Inovasi Kuliner, Jajanan

Cacalan, Keputusan

Pembelian

Keywords:

Culinary Innovation, Cheat

Snacks, Purchasing

Decisions

\section{A B S T R A K}

Tujuan penelitian ini adalah untuk mengetahui bagaimana pengaruh inovasi kuliner pada jajanan cacalan terhadap keputusan pembelian pembelian di Kecamatan Sidemen. Metode analisis pada penelitian ini yang tepat adalah analisis regresi sederhana untuk mengetahui pengaruh inovasi pada Jajanan Cacalan terhadap keputusan pembelian konsumen. Metode penelitian yang digunakan adalah metode penelitian kuantitatif untuk mencari hubungan antara dua variabel. Metode pengumpulan sampel non probability sampling yaitu purposive sampling, dengan penentuan jumlah sampel menggunakan rumus slovin. Berdasarkan hasil perhitungan dari 37.488 orang jumlah populasi, diambil secara 100 konsumen pembeli jajanan cacalan. Metode analisis pada penelitian ini yang tepat adalah analisis regresi sederhana untuk mengetahui pengaruh inovasi pada Jajanan Cacalan terhadap keputusan pembelian konsumen, proses analisis statistik dikomputasi dengan SPSS. Berdasarkan hasil penelitian dan pembahasan dapat disimpulkan bahwa terdapat pengaruh yang signifikan inovasi kuliner pada jajanan cacalan terhadap keputusan pembelian pembelian. Variabel inovasi kuliner berpengaruh 75,6\% keputusan pembelian dengan persamaan garis regresi $Y=4,646+$ 2,948X. Berdasarkan hal tersebut disarankan kepada para pedagang jajanan cacalan agar melakukan inovasi agar keputusan pembelian konsumen meningkat.

\section{A B S T R A C T}

The purpose of this study was to find out how the influence of culinary innovations on chopped snacks on purchasing purchasing decisions in Sidemen District. The analytical method in this research that is appropriate is a simple regression analysis to determine the effect of innovation on the Crap Snack on consumer purchasing decisions. The research method used is a quantitative research method to find the relationship between two variables. The method of collecting non-probability sampling is purposive sampling, by determining the number of samples using the Slovin formula. Based on the calculation results of 37,488 people, the total population was taken by 100 consumers of buyers of small-scale snacks. The analytical method in this research that is appropriate is simple regression analysis to determine the effect of innovation on Chopped Snacks on consumer purchasing decisions, the process of statistical analysis is computed with SPSS. Based on the results of the research and discussion it can be concluded that there is a significant effect of culinary innovation on chop snacks on purchasing purchasing decisions. The variable of culinary innovation influences $75.6 \%$ of purchasing decisions with the regression line equation $Y=4.646+2.948 X$. Based on this, it is recommended that the small-scale snacks traders innovate so that consumer purchasing decisions increase.

Copyright (C) Universitas Pendidikan Ganesha. All rights reserved.

\footnotetext{
* Corresponding author.

E-mail addresses: alitpujiawan@yahoo.com (A.A Ketut Alit Pujawan)
} 


\section{Pendahuluan}

Pariwisata budaya merupakan domain utama bagi pariwisata di Bali yang menjadi arah kemana perkembangan pariwisata di Bali. . Hal ini juga sejalan dengan pernyataan Ketut Sumadi Ketua Program Doktor Insititut Dharma Dalam Negri (Ekonomi.Bisnis.Com 2013) bahwa "Seni budaya dan tradisi masyarakat menjadi aset utama kepariwisataan Indonesia, karena sifatnya yang unik dan khas". Dewasa ini, pariwisata di Bali yang bebrbasis budaya dan tradisi mulai menciptakan berbagai inovasi di bidang budaya agar memiliki nilai ekonomis untuk mendatangkan keuntungan secara ekonomi. Dalam ilmu disiplin pariwisata hal tersebut lebih dikenal dengan istilah komodifikasi budaya. Masyarakat Bali mempunyai sosiologi budaya yang menjadi tumpuan kekuatan pariwisatanya. Pernyataan inovasi budaya juga pernah dilontarkan oleh Budi Santosa pada artikelnya yang berjudul Budaya Inovatif, Inovasi Budaya (Kompas, 13 November 2017) bahwa "inovasi dalam budaya diharapkan menghasilkan cara kerja dan sikap baru yang lebih bermanfaat. Dalam bidang ini kalau bias membuat inovasi, potensi pasar dalam negeri sudah cukup besar menggerakan ekonomi dalam negeri".

Budaya di Bali beragam bentuk dan penerapannya, salah satunya penerapan budaya dan tradisi melalui kuliner. Menurtu William Wongso (travel.kompas.2015) "kuliner penting sebagai budaya bangsa, identitas kita, yang selama ini tidak disadari, banyak yang tidak mengerti kuliner itu bagian dari budaya seperti tarian masuk pariwisata dan ekonomi kreatif'.Kesadaran akan keberadaan inovasi begitu penting, inovasi (Menurut Para ahli). Masyarakat Kecamatan Sidemen telah melakukan suatu inivasi pada budaya, salah satunya adalah inovasi pada Jajanan Bekayu, Suci, Saraswati yang awalnya makanan ini memiliki funsgi sebagai sarana upacara adat umat hindu dan rasa yang tidak begitu enak jika dikonsumsi kini diubah menjadi lebih layak untuk di konsumsi. Adanya perubahan pada aspek bentuk, penambahan metode memasak, peningkatan cita rasa. Inovasi pada Jajanan Bekayu, Suci maupun Saraswati dikenal dengan sebutan "Cacalan" yang saat ini telah terjadi di Kecamatan Sidemen Kabupaten Karangasem. Selain fungsi sebagai makanan yang lebih layak untuk dikonsumsi, pada dasarnya masyarakat Bali yang percaya dengan mitos masih melekat erat pada jiwanya. Salah satu mitos yang menjadi kebiasaan masyarakat Bali adalah tidak boleh menyisakan makanan apalagi membuang makanan, bahkan mitos tersebut menerbitkan sebuah adagium berbahasa Bali yaitu "nenten dados metada utawi mecarikan mangda nenten mati sipe seleme". Yang artinya "tidak boleh menyisakan atau membuang makanan agar tidak mati peliharaan" Atas dorongan itulah masyarakat Bali enggan membuang atau menyisakan makanan. Mungkin salah satu Inovasi yang terjadi pada Jajajan Bekayu, Saraswati maupun Suci menjadi Jajan Cacalan didorong atas adagium tersebut.

Hasil inovasi jajanan atau Jaje Cacalan yang dilakukan oleh masayarakat Kecamatan Sidemen kini sudah dijual di warung - warung lokal yang menjadi konsumsi masyarakat Kecamatan Sidemen selain dibuat untuk dikonsumsi diri sendiri. Berdasarkan dari fenomena tersebut, secara tidak langsung masayarakat Kecamatan Sidemen akan menyadari pentingnya keberadaan inovasi untuk menunjang pendapatan mereka. Tetapi sebuah inovasi tidak semerta - merta memberikan dampak yang begitu signifikan terhadap perekonomian mikro khususnya tingkatan rumah tangga. Begitu juga apa yang terjadi di Kecamatan Sidemen, hasil inovasi Jaje Cacalan belum diketahui seberapa besar manfaatnya, apakah inovasi tersebut menghasilkan sesuatu yang baik atau bahkan tidak memberikan kontribusi yang signifikan. Oleh karena itu perlu diuukur seberapa baik inovasi Jaje Cacalan pada Kecamatan Sidemen sehingga berpengaruh terhadap keputusan pembelian pembelian konsumen. Penelitian ini hanya dibatasi pada pengukuran inovasi Jaje Cacalan di Kecamatan Sidemen, dan penelitian ini tentunya akan berlanjut pada pengembangan Jaje Cacalan untuk dikemas sebagai produk wisata yang memberikan dampak yang positif terhadap perekonomian masyarakat Kecamatan Sidemen Kabupaten Karangasem.

Terciptanya inovasi yang terjadi pada kuliner tradisional didorong atas dasar kebiasan masyarakat Bali khususnya masyarakat Kecamatan Sidemen, Kabupaten Karangasem tidak dianjurkan untuk membuang makanan maupun menyisakan makanan. Namun inovasi yang memiliki tujuan untuk meningkakan kesejahteraan masyarakat tidak bias di generalisasi begitu saja. Keberhasilan suatu inovasi produk dipegaruhi oleh banyak factor, pada penelitian ini bermaksud untuk mengukur seberapa besar pengaruh inovasi terhadap keputusan pembelianpembelian konsumen. Berdasarkan permasalahan diatas tujuan penelitian ini adalah untuk mengetahui bagaimana pengaruh inovasi kuliner pada jajanan cacalan terhadap keputusan pembelian pembelian di Kecamatan Sidemen.

Pada penelitian ini hanya dibatasi pada pengaruh inovasi terhadap keputusan pembelianpembelian. Diharapkan setelah penelitian ini, aka ada penelitian yang memiliki pengaruhnya terhadap keuntungan ekonomi skala mikro pada pedagang Jajan Cacalan. Pada penelitian ini, penulis lebih menekankan pengaruhnya terhadap keputusan pembelianpembelian, karena inovasi yang merupakan terciptanya sebuah produk baru yang dikatakan berhasil atau tidaknya diukur berdasarkan minat 
konsumen terhadap produk tersebut. Sehingga salah satu indicator yang menjadi keberhasilan sebuah inovasi adalah keputusan pembeliankonsumen untuk memilih produk tersebut.

\section{Metode}

Pada penelitian ini terdapat dua variable, yaitu variable indenpenden yang mempengaruhi variable dependen. Maka metode analisis pada penelitian ini yang tepat adalah analisis regresi sederhana untuk mengetahui pengaruh inovasi pada Jajanan Cacalan terhadap keputusan pembelian konsumen. Sugiyono (2010: 270) menjelaskan bahwa analisis regresi sederhana didasarkan pada hubungan fungsional ataupun kausal satu variabel independen dengan satu variabel dependen.

Pada penelitian ini menggunakan metode pengumpulan sampel non probability sampling. Non probability sampling merupakan teknik pengambilan sampel yang tidak memberikan peluang yang sama bagi setiap anggota yang dipilih sebagai sample (Sugiyono; 2011). Menurut sugiyoo (2008:116) sampel merupakan bagian dari populasi yag telah dipilih sesuai dengan karakteristiknya. Lebih detailnya penelitian ini menggunakan purposive sampling, yang menurut Sugiyono (2017) merupakan teknik pengambilan sampel dengan pertimbangan tertentu.

Pada penelitian ini memberikan batasan kesalahan 10\% dengan harapan keakuratan $90 \%$. Sehingga peneliti menentukan batas minimal yang dapat memenuhi syarat margin of eror $10 \%$ dengan masukan margin eror tersebut ke dalam formula atau rumus slovin.

$$
n=\frac{N}{1+N e^{2}}
$$

\section{Keterangan:}

$$
\begin{array}{ll}
\mathrm{n} & \text { : Jumlah Sampel } \\
\mathrm{N} & \text { :Jumlah Populasi } \\
\mathrm{e} & \text { : Margin Eror }
\end{array}
$$

Maka dapa diperoleh perhitungan jumlah sampel yang diperlukan dengan populasi kecamatan sidemen sebesar 37.488 jiwa (BPS; 2018) adalah sebagai berikut:

$$
\begin{aligned}
& \mathrm{n}=37.488 /\left(1+\left(37.488 \times 0,1^{2}\right)\right) \\
& \mathrm{n}=37.488 /(1+(37.488 \times 0,01)) \\
& \mathrm{n}=37.488 / 375,88 \\
& \mathrm{n}=100
\end{aligned}
$$

Sehingga jumlah sampel yang diperlukan pada penelitian ini adalah sebesar 100 konsumen pembeli jajanan cacalan dengan margin eror $10 \%$.

Hubungan variable antara variable independen dengan variable dependen pada penelitian ini hanya analisis regresi sederhana, yang mana variable independen mempengaruhi variable dependen. Alat analisis yang digunakan pada penelitian adalah SPSS. Pada hubungan pengaruh antara variable, $\mathrm{X}$ berperan sebagai variable indenpenden dan Y berperan sebagai variable dependen. Berikut ini adalah variable dalam penelitian ini:

Inovasi Produk memiliki peran sebagai variable independen yang diberikan symbol X. Pengukuran inovasi produk pada Jajanan Cacalan menggunakan teori Lukas dan Ferrell (2000: 240) menjelaskan adanya beberapa indicator dari inovasi produk, yaitu:

a) Perluasan lini (line extension) yaitu produk yang dihasilkan tidaklah benar - benar baru tetapi relative baru untuk sebuah pasar: (1) Jajanan Cacalan melengkapi produksi jajanan tradisional lainnya yang telah ada. X.1; (2) Jajanan Cacalan menjadikan jajanan tradisional menjadi poduk yang lebih beragam, sehingga memunculkan banyak pilihan. X.2

b) Produk Baru (me too - product) yaitu produk baru bagi perusahaan tetapi tidak baru bagi pasar: (1) Jajanan Cacalan merupakan jajanan yang belum pernah diproduksi oleh masyarakat lainnya di Bali. X.3; (2) Jajanan Cacalan memiliki ciri khas yang berbeda dengan jajanan lainnya terutama pada Jajanan Bekayu atau Suci. X.4

c) Produk benar - benar baru (new -to - the -world - product) adalah produk yang termasuk baru baik bagi perusahaan maupun pasar: Jajanan Cacalan memiliki rasa dan tekstur berbeda dengan Jajanan Bekayu atau Suci. X.5 
Pada variable keputusan pembelianpembelian ini diberikan symbol Y. pendekatan yang digunakan dalam mengukur keputusan pembelianpembelian konsumen menggunakan teori Engel et al (2006): (a) Jajanan sebagai cemilan tepat untuk dibeli. Y.1; (b) Pengambilan keputusan untuk membeli Jajanan Cacalan relative singkat Y.2; (c) Membeli Jajanan Cacalan secara berulang - ulang. Y.3.

Instrument yang digunakan kuisioner yang disebarkan ke setiap responden yang memenuhi kriteria. Pengukuran setiap indicator yang tertera pada kuisioner menggunakan skala likert dengan bentuk sebagai berikut: Sangat Setuju. Setuju, Ragu - Ragu, Tidak Setuju, Sangat Tidak Setuju. Jawaban mempunyai gradasi dari sangat positif sampai sangat negative, berikut interpretasi skor berdasarkan interval. Rumus Interval (I) = 100/ Jumlah Skala Likert, maka I = $100 / 5=20$. Sehingga hasil interval skor persen adalah interval 20 .

Tabel 1. Sekala Likert

\begin{tabular}{cc}
\hline Interval & Kriteria \\
\hline $0-19,9$ & Sangat Tidak Setuju \\
$20-39,9$ & Tidak Setuju \\
$40-59,9$ & Ragu - ragu \\
$60-79,9$ & Setuju \\
$80-100$ & Sangat Setuju \\
\hline
\end{tabular}

Berdasarkan dari teori mengenai inovasi yaitu, Sebuah inovasi dikatakan sukses jika produk baru yang dibuat sudah diterima dan dikenal oleh masyaraakat luas, proses ulai dikenalkan hingga digunakan oleh masyarakat inilah yang disebut proses disfusi. Rogers dalam Suryani (2008:305) menjelaskan bahwa inovasi merupakan sebuah proses yang perlu dikomunikasikan melalui chanel tertentu, dengan jangka waktu tertentu diantara anggota suatu system social. Maka peneliti memiliki H : Inovasi produk Jajanan Cacalan berpengaruh terhadap keputusan pembelian konsumen di Kecamatan Sidemen, Kabupaten Karangasem.

\section{Hasil dan pembahasan}

Pada penelitian ini, metode pengumpulan data yang digunakan dengan cara mengantarkan langsung kuisioner kepada responden yang berada di Kecamatan Sidemen Kabupaten Karangasem. Responden pada penelitian ini adalah pedagang Jaje Cacalan dan konsumen yang membeli. Responden yang diperoleh oleh peneliti berfokus pada 10 (sepuluh) pedagang yang menjual Jaje Cacalan dan rata rata dagang yang beroperasi lebih dari 3 tahun. Jarak setiap pedagang yang menjual Jaje Cacalan relative dekat, dan penjualan Jaje Cacalan ini paling banyak setelah adanya hari raya agama. Pada saat selesainya upacara adat pada hari raya tertentu banyak sisa Jaje Cacalan yang diolah kembali sehingga layak untuk di konsumsi dan memiliki rasa yang lebih baik dibandingkan dengan jajanan pada saat masih berwujud Bekayu atau Pesucian.

Dalam penyebaran kuisoner pada konsumen di 10 titik pedagang di Kecamatan Sidemen, Kabupaten Karangasem dengan menyebarkan 100. Kuisioner. Setiap kuisioner yang diberikan kepada pembeli (konsumen) dan diharapkan agar responden dapat mengisi pertanyaan - pertanyaan pada kuisioner sesuai dengan keadaan sebenarnya. Dari 150 kuisiner yang disebarkan pada 10 titik pedagang seluruhnya dapat diolah menjadi data yang berguna bagi kelanjutan penelitian ini. Kuisioner yang disebarkan kepada responden, dengan distribusi penyebaran yang tertera pada Tabel 2.

Tabel 2. Distribusi Penyebaran Kuisioner

\begin{tabular}{lcc}
\hline \multicolumn{1}{c}{ Nama Pedagang } & Kuisioner Disebar & Kuisioner Kembali \\
\hline Ni Komang Darmi & 15 & 10 \\
I Nengah Sadri & 15 & 11 \\
Nyoman Munek & 15 & 9 \\
I Wayan Karsa & 15 & 10 \\
I Wayan Lemek & 15 & 10 \\
Kadek Sri & 15 & 10 \\
Komang Soka & 15 & 13 \\
\hline
\end{tabular}




\begin{tabular}{lcc}
\hline Nengah Yasa & 15 & 10 \\
Wayan Darmi & 15 & 7 \\
Wayan Pageh & 15 & 10 \\
Total Responden & $\mathbf{1 5 0}$ & $\mathbf{1 0 0}$ \\
\hline
\end{tabular}

Sumber: Data Primer yang diolah, 2018

Kriteria responden pada penelitian ini adalah para pembeli yang sudah memasuki usia produktif dan tentunya pernah mencoba Jajanan Bekayu dan Pesucian yang belum diolah menjadi Jajanan Cacalan. Adapun rincian deskripsi responden dilihat pada Table 3.

Tabel 3. Deskripsi Responden

\begin{tabular}{|c|c|c|c|}
\hline NO & Kriteria & Jumlah & Persentase (\%) \\
\hline \multirow[t]{4}{*}{1} & Jenis Kelamin: & & \\
\hline & Laki - Laki & 63 & $63 \%$ \\
\hline & Perempuan & 37 & $37 \%$ \\
\hline & Total Responden & 100 & $100 \%$ \\
\hline \multirow[t]{5}{*}{2} & Usia (tahun) & & \\
\hline & $20-29$ & 4 & $4 \%$ \\
\hline & $30-39$ & 30 & $30 \%$ \\
\hline & $40-49$ & 66 & $66 \%$ \\
\hline & Total Responden & 100 & $100 \%$ \\
\hline \multirow[t]{5}{*}{3} & Lama Berlangganan (tahun) & & \\
\hline & $1 / 2-1$ & 37 & $37 \%$ \\
\hline & $1-3$ & 53 & $53 \%$ \\
\hline & $>3$ & 10 & $10 \%$ \\
\hline & Total Responden & 100 & $100 \%$ \\
\hline
\end{tabular}

Sumber: Data Primer yang Diolah tahun 2018.

Keterangan pada Tabel 3 menunjukan responden yang berjenis kelamin laki - laki yang mengkonsumsi Jajanan (Jaje) Cacalan sebanyak 63 orang dan jumlah responden pada jenis kelamin perempuan sebesar 37 orang. Hal tersebut menunjukan bahwa responden yang mendominasi dalam melakukan pembelian Jajanan Cacalan (Jaje Cacalan) adalah responden jenis kelamin laki - laki.

Jika dilihat berdasarkan pengelompoka usia, responden dengan usia yang berada pada rentang 20 - 29 tahun sebanyak 4 orang yang membeli jajanan tersebut. Kemudian untuk responden dengan rentang usia antara 30- 39 tahun sebanyak 30 responden dan yang terakhir adalah responden yang berada diantara umur 40- 49 tahun sejumlah 66 orang. Maka responden berdasarkan pengelompokan usia didominasi oleh rentang usia antara 40-49 tahun. Keterangan pada Tabel 3 menunjukan bahwa responden berdasarkan pengelompokan lama menjadi pelanggan anatara $6-12$ bulan sebesar 37 orang, $1-3$ tahun terdiri dari 13 orang dan diatas 3 tahun sebanyak 10 orang. Berdasarkan keterangan tersebut terlihat bahwa responden pada penelitian ini sebagian besar menjadi konsumen selama 6 -12 bulan.

Dalam upaya memperoleh gambaran mengenai variable inovasi produk kuliner tradisional terdiri dari 3 komponen. Adapun 3 komponen tersebut adalah sebagai berikut; 1. Pembaharuan Jenis Produk,2. Peningkatan Kualitas, 3. Macam model kemasan terhadap keputusan pembelian pada objek penelitian usaha skala mikro. Hal tersebut dapat ditunjukkan pada Tabel 4.

Tabel 4. Variabel Inovasi Produk

\begin{tabular}{|c|c|c|c|c|c|c|c|c|c|c|}
\hline \multirow[b]{2}{*}{ No } & \multirow[b]{2}{*}{ Indikator } & \multicolumn{7}{|c|}{ Sko } & \multirow{2}{*}{\multicolumn{2}{|c|}{$\begin{array}{cc}\text { Rata- } & \text { Rata - rata } \\
\text { rata } & \text { dimensi/kateg } \\
\text { skor } & \text { ori } \\
\end{array}$}} \\
\hline & & стT & & $\mathbf{N}$ & c & CS & & otal & & \\
\hline \multicolumn{2}{|c|}{$\begin{array}{l}\text { Perluasan Lini (Line Extention) } \\
\end{array}$} & & & & & & & & & \\
\hline 1 & $\begin{array}{l}\text { JajananCacalan melengkapi } \\
\text { produksijajanantradisionallain }\end{array}$ & & 0 & 0 & 10 & 45 & 45 & 8695 & 86.9 & 5 Sangat Setuju \\
\hline
\end{tabular}




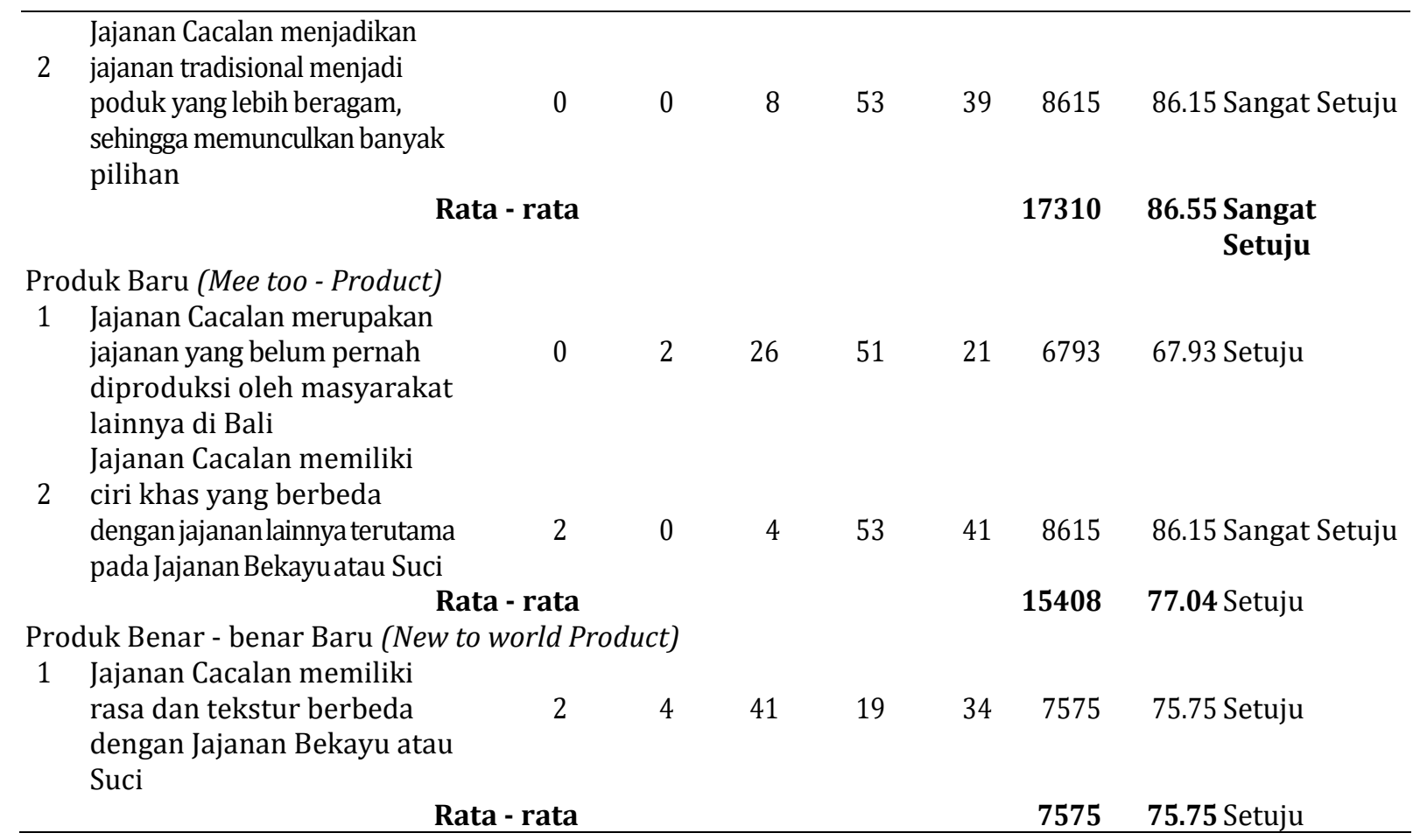

Sumber: Data Primer yang Diolah 2018

Berdasarkan table 4.3 pada indicator perluasan lini (line extention) pada indicator X.1 dan X.21 memperoleh hasil sangat setuju dari responden. Kemudian pada indicator produk baru (mee too product) pada pertanyaan X.3 memperoleh hasil setuju dan pada pertanyaan X.4 memperoleh hasil sangat setuju, sehingga hasil yang diperoleh adalah setuju pada indicator produk baru (mee too product). Pada indicator produk benar - benar baru (new to world product) pada pertanyaan X.5 memperoleh hasil setuju sehingga hasil yang diperoleh adalah setuju.

Tabel 5. Variabel Keputusan Pembelian

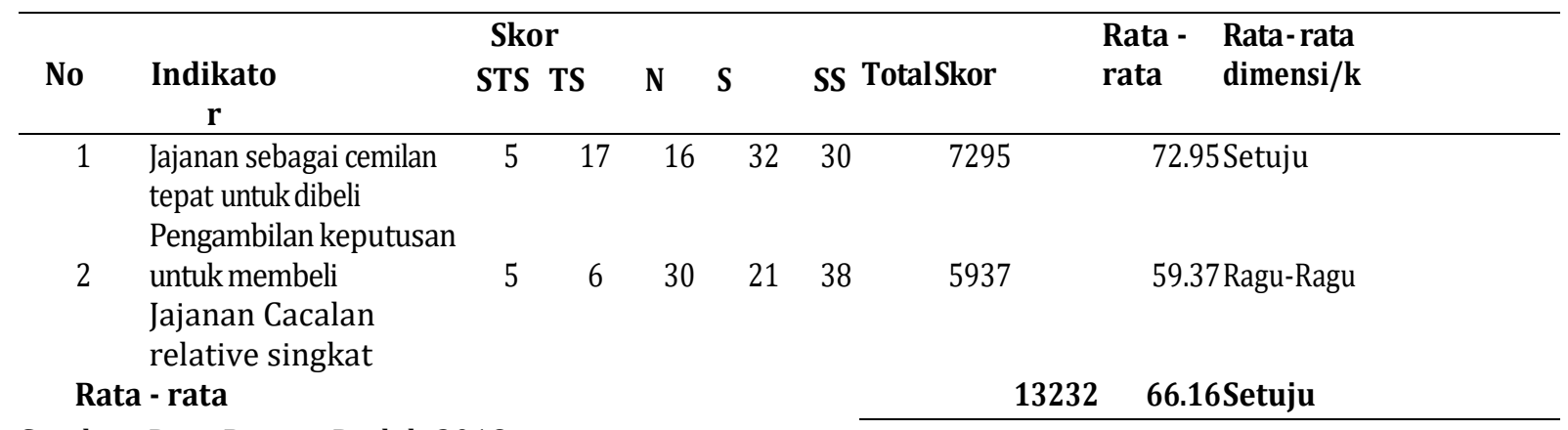

Sumber: Data Primer Diolah 2018

Pada Table 5 yang memaparkan nilai tentang variable keputusan pembelian, pada petanyaan Y.1 memperoleh kategori "setuju" sedangkan pada pertanyaan Y.2 memperoleh penilaian "ragu-ragu". Pada akhirnya penilaian responden terhadap variable keputusan pembelian adalah "setuju".

Uji validitas digunakan untuk mengukur sah atau valid tidaknya suatu kuisioner. Kuisioner dianggap valid apabila pertanyaan pada kuisioner mampu untuk mengungkapkan suatu yang diukur oleh kuisioner tersebut. Pengujian validitas dalam penelitian ini dilakukan dengan menggunakan Pearson Correlation. Item pertanyaan yang memiliki nilai korelasi signiifikansi level dibawah $10 \%$. Hasil pengujian validitas data disajikan pada tabel 4.5 sebagai berikut: 
Tabel 6. Uji Validitas Variabel Inovasi Produk

\begin{tabular}{|c|c|c|c|}
\hline Item & $\begin{array}{c}\text { Pearson } \\
\text { Correlation }\end{array}$ & R Tabel & Keterangan \\
\hline$\overline{\mathrm{X} 1}$ & 0,954 & 0,1638 & Valid \\
\hline $\mathrm{X} 2$ & 0,979 & 0,1638 & Valid \\
\hline X3 & 0,893 & 0,1638 & Valid \\
\hline $\mathrm{X} 4$ & 0,952 & 0,1638 & Valid \\
\hline X5 & 0,982 & 0,1638 & Valid \\
\hline
\end{tabular}

Sumber: Data primer yang diolah 2018

Tabel 7. Uji Validitas Keputusan Pembelian

\begin{tabular}{llll}
\hline Item & $\begin{array}{l}\text { Pearson } \\
\text { Correlation }\end{array}$ & R Tabel & Keterangan \\
\hline Y1 & 0,865 & 0,1638 & Valid \\
Y2 & $0,896^{*}$ & 0,1638 & Valid \\
\hline
\end{tabular}

Sumber: data primer yang diolah 2018

Berdasarka Tabel 6 dan 7 di atas, dapat dilihat hasil pengujian yang dilakukan menunjukan bahwa koefesien pearson correlation untuk setiap skor total item minimalnya $>\mathrm{R}$ tabel dan jika skor total item pengukuran inovasi produk dan keputusan pembelian yang skor totalnya $<\mathrm{R}$ tabel maka item tersebut tidak valid.

Uji rekiabiitas yang digunakan yaitu teknik Cronbach's Alpa dimana variabel atau konstruk dikatakan reliable jika nilai Cronbach's Alpa $>0,93$. Semakin nilai alpanya mendekati satu maka nilai reliabilitas datanya semakin terpercaya untuk masing - masing variabel. Hasil pengujian reliabilitas data dapat dilihat pada tabel 4.6 sebagai berikut:

Tabel 8. Hasil Uji Reliabilitas

\begin{tabular}{llll}
\hline Variabel & Cronbach's Alpa & \multicolumn{1}{c}{ R tabel } & Keterangan \\
\hline Y1 & 0,905 & 0,1638 & Valid \\
Y2 & 0,911 & 0,1638 & Valid \\
\hline
\end{tabular}

Sumber: data primer yang diolah, 2018

Dari data tabel diatas dapat disumpulkan bahwa pertanyaan - pertanyaan dari variabel variabel tersebut $>0,1638$ dan tidak ada satupun yang $<0,1638$. Dengan mengacu pada tabel diatas maka semua butir pertanyaan dalam variabel dalam penelitian adalah handal, sehingga butir-butir pernyataan dalam variabel penelitian dapat digunaka dalam penelitian ini.

Setelah dilakukan uji prasyarat menunjukkan bahwa data terdistribusi normal, linier, dan tidak mengalami heterokedasitas maka dilakukan uji parametrik yaitu analisis regresi sederhana.

Model statistic yang digunakan untuk menguji hipotesis pada penelitian ini adalah dengan menggunakan analisis regresi. Hasil pengujian untuk hipotesis dapat dilihat pada Tabel 9:

Tabel 9. Hasil Uji F

\begin{tabular}{cccc}
\hline Variabel & F Hitung & Sig & Kesimpulan \\
\hline Inovasi Produk & 303,278 & 0.00 & $\mathrm{H}_{0}$ ditolak \\
\hline
\end{tabular}

Sumber: Data Primer yang diolah 2018

Uji hoptesis regresi linear sederhana terhadap pengaruh antara variabel inovasi produk terhadap keputusan pembelian mempunyai signifikansi sebesar 0,00 . Variable bebas dapat dikatakan berpengaruh terhadap varibel terikat jika nilai signifikansi dibawah 0.05 atau nilai signifikansi uji hipotesis $<$ sig 0.05 . Sehingga berdasarkn nilai signifikansi variable bebas yaitu inovasi produk mempengaruhi variable bebas yaitu keputusan pembelian. 
Model statistic yang digunakan untuk menguji hipotesis pada penelitian ini adalah dengan menggunakan analisis korelasi bivariate. Hasil pengujian untuk keempat hipotesis dapat dilihat pada Tabel 10

Tabel 10 Hasil Uji Regresi Sederhana

\begin{tabular}{ccccc}
\hline Variabel & $\mathrm{R}$ & $\mathrm{R}^{2}$ & $\mathrm{Sig}$ & Kesimpulan \\
\hline Inovasi Produk & 0,869 & 0,756 & 0,000 & Terdapat korelasi \\
\hline
\end{tabular}

Sumber : Data Primer yang diolah 2018

Korelasi antara variabel inovasi produk terhadap keputusan pembelian mempunyai signifikansi sebesar $0,00<0,05$, dan hasil uji korelasinya adalah positif 0,869 , artinya bahwa untuk variabel ini hubungannya kuat dan signifikan. Hasil kuadrat R menunjukkan 75,6\% keputusan pembelian dipengaruhi oleh inovasi kuliner pada jajanan cacalan, sisanya dipengaruhi oleh variabel lain. Persamaan garis regresi yang diperoleh adalah:

$$
Y=4,646+2,948 X
$$

Hasil penelitian ini menunjukan bahwa analisis korelasi yang digunakan untuk menguji pengaruh inovasi terhadap keputusan pembelian yang terjadi pada Jajanan Cacalan di Kecamatan Sidemen Kabupaten Karangasem memiliki pengaruh. Dengan kata lain, inovasi yang diterapkan pada Jajanan Bekayu atau Pesucian yang biasanya digunakan sebagai jajanan persembahan dan cenderung memiliki rasa yang tidak enak dan tekstur keras, diubah menjadi Jajanan jenis baru tergolong berhasil.

Keputusan pembelian yang memberikan nilai positif terhadap inovasi Jajanan Cacalan dapat juga digunakan sebagai parameter bahwa inovasi yang diterapkan masyarakat Sidemen, Kabupaten Karangasem sangat baik. Hal tersebut didukung oleh penelitian Situmorang dan Wijaksana (2014) bahwa bahwa tingkat penggunaan inovasi produk memiliki pengaruh positf terhadap keputusan pembelian sebesar 0,304. Sebuah inovasi dikatakan sukses jika produk baru yang dibuat sudah diterima dan dikenal oleh masyaraakat luas, proses ulai dikenalkan hingga digunakan oleh masyarakat inilah yang disebut proses disfusi. Rogers dalam Suryani (2008:305) menjelaskan bahwa inovasi merupakan sebuah proses yang perlu dikomunikasikan melalui chanel tertentu, dengan jangka waktu tertentu diantara anggota suatu system social. Hail penelitian ini juga didukung oleh penelitian Taan, H. (2017) yang menemukan bahwa inovasi produk berpengaruh positif terhadap keunggulan bersaing, yang artinya juga memperkuat keputusan pembelian oleh pelanggan. Penelitian Deo and Hosee (2017) menemukan bahwa ada hubungan yang signifikan dan positif antara inovasi pengemasan produk dan perilaku pembelian bir di Rwanda. Penelitian tersebut juga menunjukkan bahwa inovasi kemasan produk berkontribusi positif terhadap perilaku keputusan pembelian konsumen pada tingkat 97,7\%. Sangat direkomendasikan kepada pedagang jajanan cacalan bahwa mereka harus inovasi produk yang baik. Jika mereka menerima atau memperkenalkan inovasi kuliner jajanan cacalan yang buruk atau bersifat konvensional maka itu bisa menjadi salah satu penyebab kegagalan produk jajanan di pasar, artinya tidak laku/keputusan pembelian rendah. Penting untuk menetapkan standar inovasi kuliner dan menerapkan strategi yang sesuai untuk perlindungan dan promosi produkkuliner yang lebih baik. Seng (2016)mengemukakan peningkatan kegiatan ekonomi globalisasi, integrasi pasar secara bertahap dan evolusi terus-menerus dari kebutuhan dan keinginan konsumen telah memberikan tantangan baru bagi perusahaan untuk terus berinovasi, terutama melakukan inovasi produk. Di bawah atmosfer baru ini menjadi penting bagi perusahaan untuk menyesuaikan diri dengan perubahan ini untuk mempertahankan pasarnya, dan untuk menghadapi persaingan agresif pada era revolusi industri 4.0 ini. Pengaruh inovasi produk terhadap niat pembelian konsumen berpengaruh positif (Seng, 2016), semakin produk suatu perusahaan dalam perdagangan inovatif, maka niat beli konsumen semakin tinggi. Hubunganya dengan hasil penelitian ini adalah semakin baik inovasi dan juga diterima oleh masyarakat Sidemen makan keputusan pembelian yang dilakukan oleh masyarakat Sidemen akan positif, begitu juga sebaliknya. Inovasi jika dikaji lebih dalam secara tidak langsung akan memberikan dampak yang positif terhadap perekonomian baik skala mikro maupun makro. Maka diperlukan penelitian lebih lanjut terkait dengan dampak terhadap ekonomi mikro di Kecamatan Sidemen, Kabupaten Karangasem.

Berbeda dengan temuan Virgiawan (2018) bahwa inovasi Produk tidak berpengaruh signifikan terhadap Keputusan Pembelian Ichi Shusi Gresik. Hal tersebut diduga karena jenis produk dan karakteristik pelanggan yang berbeda menyebabkan adanya perbedaan persepsi terkait hubungan inovasi produk dan keputusan pembelian. 


\section{Simpulan dan saran}

Berdasarkan hasil penelitian dan pembahasan dapat disimpulkan bahwa terdapat pengaruh yang signifikan inovasi kuliner pada jajanan cacalan terhadap keputusan pembelian pembelian. Variabel inovasi kuliner berpengaruh 75,6\% keputusan pembelian dengan persamaan garis regresi $Y=4,646+$ 2,948X. Berdasarkan hal tersebut disarankan kepada para pedagang jajanan cacalan agar melakukan inovasi agar keputusan pembelian konsumen meningkat

\section{Daftar Rujukan}

Engel, James et al. 2006. Consumer Baehavior. Mason: Permission Department, Thomson Business \& economic.

Freddy Frangkutti (2002) The Power of Brand, Teknik Mengelola Brand Equity dan Pengembangan Merk. Jakarta : Gramedia Pustaka.

Hermana, Budi. (2008). Mendorong daya saing di Era Globalisasi dan Informasi: Pemanfaatan Model Intelektual dan Teknologi Informasi Sebagai Basis Inovasi di Perusahaan. Universitas Gunadarma.

https://www.longtripmania.org/2012/09/long-trip-di-kecamatan-sidemen.html https://issuu.com/epaper-kmb/docs/bpo_15112015/8

Lucas, B.A. dan Ferrel, O.C.T. (2000): The Effect of Market Orientation on Product Innovation, Journal of Academy of Marketing Science, 28 (2) 239-247.

Murajad Kuncoro. 2008. "Strategi Pengembangan Pasar Modern dan Tradisional”. Kadin Indonesia.

Pearce II, John A. dan Robinson Richard B.Jr. (2008). Manajemen Strategi 10. Salemba Empat. Jakarta.

Sugiyono. 2005. Memahami Penelitian Kuantitatif. Bandung : Alfabeta

Sugiyono. 2010. Metode Penelitian Pendidikan Pendekatan Kuantitatif, kualitatif, dan R\&D. Bandung: Alfabeta

Sumaryani, Komang., Putu Agustini, dan Nanak Antarini. 2014. Identifikasi Rhodamin B pada Jajan Kembang Goyang dan Jajan Sirat di Desa Pekutatan Kabupaten Jembrana. Jurnal Ilmu Gizi, 5(1), 4451

Suryani, Tatik. 2008. Perilaku Konsumen; Implikasi Strategi Pemasaran. Yogyakarta: Graha Ilmu.

Virgiawan, Virgo. 2018. Analisis Pengaruh Kualitas Produk, Kualitas Pelayanan, Lokasi Dan Inovasi Produk Terhadap Keputusan Pembelian Di Ichi Sushi Gresik. (thesis dipublis online) Universitas Muhammadiyah Gresik: Manajemen, Fakultas Ekonomi dan Bisnis, Universitas Muhammadiyah Gresik

Taan, H. 2017. Pengaruh Inovasi Produk dan Harga terhadap Keunggulan Bersaing Usaha Karawo di Kota Gorontalo. Jurnal bisnis dan kewirausahaan Vol. 6 No. 2: 148-158

Deo, M. and Hosee, N. 2017. Product Packaging Innovation and Consumer Buying Behavior in Rwanda. International Journal of Social Science and Humanity, Vol. 7, No. 6: 344-349

Seng, L.C. 2016. The Influence Of Product Innovation Toward Consumer Purchase Intention. International Journal of Economics. Commerce and Management United Kingdom Vol. IV, Issue 4: 773-782

Situmorang, R.Y., dan Wijaksana, T.I. 2014. Pengaruh Tingkat Penggunaan Inovasi Produk Terhadap Keputusan pembelian konsumen jnc cookies. Bandung: Ilmu Administrasi Bisnis, Fakultas Komunikasi Dan Bisnis, Universitas Telkom. 